\title{
BENEFICIAL OUTCOMES AFTER COMBINED THERAPY WITH AZATHIOPRINE AND PIOGLITAZONE IN PRECLINICAL ARTHRITIC MODELS
}

\author{
VEERESH BABU PRATAP*, SOUNDARYA VARLA, GANGA RAJU M
}

Department of Pharmacology, Gokaraju Rangaraju College of Pharmacy, Bachupally, Hyderabad, Telangana, India. Email: pratap.veeresh@gmail.com

Received: 21 November 2018, Revised and Accepted: 31 January 2019

\section{ABSTRACT}

Objectives: The present study was designed to investigate the antioxidant and anti-arthritic activities of azathioprine-pioglitazone combination therapy to check whether it has an add on benefit over monotherapy with azathioprine or pioglitazone on disease activity in rodent models.

Methods: The antioxidant activity of test drugs and their combination was screened by $\mathrm{H}_{2} \mathrm{O}_{2}$ and nitric oxide scavenging assays. They were further evaluated for anti-arthritic activity using in vitro models such as protein denaturation and membrane stabilization and in vivo methods such as formaldehyde and complete Freund's adjuvant (CFA)-induced arthritis.

Results: The combination of test drugs showed better inhibition of free radicals in both $\mathrm{H}_{2} \mathrm{O}_{2}$ and nitric oxide scavenging assay than individual counterparts revealing its potential antioxidant activity. They also showed significant inhibition of protein denaturation and proliferation of the red blood cell in in vitro models. The test drugs showed significant inhibition of the paw volume in both the formaldehyde and CFA-induced arthritis along with reverting the altered biochemical parameters. These findings were corroborated by radiological and histopathological studies.

Conclusions: Combination of azathioprine and pioglitazone exhibited better antioxidant and anti-arthritic effect than the individual drugs showing synergistic interaction between them.

Keywords: Azathioprine, Pioglitazone, Arthritis, Formaldehyde, Complete Freund's adjuvant.

(C) 2019 The Authors. Published by Innovare Academic Sciences Pvt Ltd. This is an open access article under the CC BY license (http://creativecommons. org/licenses/by/4. 0/) DOI: http://dx.doi.org/10.22159/ajpcr.2019.v12i3.30902

\section{INTRODUCTION}

Free radicals or reactive oxygen species (ROS) are highly unstable molecules produced during normal cellular metabolism by living organisms [1]. Imbalance between oxidants and antioxidants is termed as "oxidative stress" [2]. Oxidative stress is the predominant predisposing factors of diseases such as cancer, diabetes, rheumatoid arthritis (RA), and neurodegenerative disorders. Hydrogen peroxide and nitric oxide are the major free radicals which are involved in the development of autoimmune disorders such as RA and systemic lupus erythematosus [3].

RA is a chronic and systemic autoimmune joint disease that is characterized by non-specific inflammation of peripheral joints and destruction of cartilage and bone with resultant disability [4]. RA affects $0.5 \%-1 \%$ of adults in industrialized countries. Its incidence and prevalence are higher in women than in men, and in older adults than in younger ones $[5,6]$. Tumor necrosis factor (TNF)- $\alpha$, interleukin (IL)- $1 \beta$, and IL-6 are major proinflammatory cytokines that play a key role in the pathological process of RA [7]. Its typical pathological findings are synovial hyperplasia, inflammatory cell infiltration, pannus formation, articular cartilage damage, bone erosion as well as extra-articular manifestations [8,9]. Joint swelling, joint pain, reduced ability to move the joint, redness of the skin around a joint, and morning stiffness are the symptoms of RA [5]. Diseasemodifying antirheumatic drugs, nonsteroidal anti-inflammatory drugs, corticosteroids, and biologic drugs are the main agents used to treat RA in the current clinic. However, lack of optimum efficacy and potential safety concerns limit their long-term use as monotherapy in RA, and therefore, combination therapy is recommended $[10,11]$.

Azathioprine constitutes a mainstay in the therapy of RA. Its suggested mechanisms include (i) inhibition of DNA synthesis, (ii) inhibition of clonal proliferation during the induction phase of the immune response, and (iii) suppression of cell-mediated and antibody-mediated immune reactions [12].
Pioglitazone, an oral antidiabetic agent, acts as a ligand for peroxisome proliferator-activated receptor gamma. It suppresses the production of inflammatory cytokines and matrix metalloproteinases [13] and causes inhibition of proinflammatory gene expression [14]. Further, it causes induction of apoptosis in macrophages and T-lymphocytes which are vital in perpetuating the RA disease progress $[15,16]$. Some experiments have shown the efficacy of pioglitazone in preclinical arthritic models.

For both azathioprine and pioglitazone exert anti-inflammatory actions in inflamed joints through different mechanisms, it was assumed that azathioprine and pioglitazone combination therapy might have synergistic efficacy in patients with RA.

In the above context, the present study was conducted to explore add on the benefit of azathioprine and pioglitazone combination therapy over monotherapy with azathioprine or pioglitazone in animal models.

\section{MATERIALS AND METHODS}

Materials

Azathioprine was purchased from Rakshit Drugs Private Limited, Hyderabad. Pioglitazone was purchased from Hetero Drugs Limited, Hyderabad. Chemicals and reagents used were of analytical grade. Complete Freund's adjuvant (CFA) was procured from Sigma-Aldrich Corporation, Mumbai.

\section{Animals}

Wistar albino rats (Approx. 150-200 g) were procured from Albino research, Hyderabad. The care and maintenance of the animals were carried out as per the approved guidelines of the Committee for the Purpose of Control and Supervision of Experiments on Animals (Registration number: 1175/PO/Re/S/08/CPCSEA) 


\section{Methods}

\section{In vitro antioxidant assays}

Hydrogen peroxide radical scavenging assay

A solution of hydrogen peroxide $(40 \mathrm{mM})$ was prepared in phosphate buffer (pH 7.4). Drugs at the concentration of $10 \mathrm{mg} / 10 \mu \mathrm{L}$ were added to $0.6 \mathrm{~mL}$ of $\mathrm{H}_{2} \mathrm{O}_{2}$ solution. The total volume was made up to $3 \mathrm{~mL}$ with phosphate buffer. The absorbance of the reaction mixture was recorded at $230 \mathrm{~nm}$. The blank solution contained phosphate buffer without $\mathrm{H}_{2} \mathrm{O}_{2}$ [17].

Hydrogen peroxide activity $(\%)=$ Abs control - Abs sample/Abs control $\times 100$

Nitric oxide scavenging activity

Nitric oxide scavenging activity can be estimated using Griess-ilosvay reaction. Nitric oxide scavenging activity was measured using a spectrophotometer. Drug was prepared in DMSO, was added to different test tubes in varying concentrations sodium nitroprusside ( $5 \mathrm{mM})$ in phosphate buffer was added to each test tube to make volume up to $1.5 \mathrm{~mL}$. Solutions were incubated at $25^{\circ} \mathrm{C}$ for $30 \mathrm{~min}$. Add $1.5 \mathrm{~mL}$ of Griess reagent (1\% sulfanilamide, $0.1 \%$ naphthyl ethylenediamine dichloride, and $3 \%$ phosphoric acid) was added to each test tube. The absorbance was measured, immediately, at $546 \mathrm{~nm}$ and the percentage of scavenging activity was measured with reference to ascorbic acid as standard [18].

Nitric oxide scavenging activity $(\%)=$ Abs control - Abs sample/Abs control $\times 100$

\section{In vitro evaluation of anti-arthritic activity}

Inhibition of protein denaturation method

The reaction mixture $(0.5 \mathrm{~mL})$ consisted of $0.45 \mathrm{~mL}$ bovine serum albumin (5\% aqueous solution) and $0.05 \mathrm{~mL}$ of test drugs (100 and $200 \mu \mathrm{g} / \mathrm{mL}$ of final volume). $\mathrm{pH}$ was adjusted to $6.3 \mathrm{using}$ a small amount of $1 \mathrm{~N} \mathrm{HCl}$. The samples were incubated at $37^{\circ} \mathrm{C}$ for $20 \mathrm{~min}$ and then heated at $57^{\circ} \mathrm{C}$ for $3 \mathrm{~min}$. After cooling the samples, $2.5 \mathrm{~mL}$ phosphate buffer saline ( $\mathrm{pH}$ 6.3) was added to each tube. Turbidity was measured spectrophotometrically at $660 \mathrm{~nm}$. For control tests, $0.05 \mathrm{~mL}$ distilled water was used instead of test drug [19]. The percentage inhibition of protein denaturation was calculated as follows:

Percentage inhibition $=100 \times 1-($ absorbance of test sample $/$ absorbance of control).

Membrane stabilization method

Fresh rat blood was collected into a centrifuge tube containing $0.5 \mathrm{~mL}$ of $200 \mathrm{mM}$ ethylenediaminetetraacetic acid. The tubes were centrifuged at $3000 \mathrm{rpm}$ for $15 \mathrm{~min}$ and washed thrice with an equal volume of normal saline. The volume of red blood cell (RBC) was measured and reconstituted as $10 \% \mathrm{v} / \mathrm{v}$ suspension with normal saline [20].

Hypotonic solution induced hemolysis

The reaction mixtures $(4.5 \mathrm{~mL})$ consisted of $2 \mathrm{~mL}$ hypotonic saline $(0.25 \% \mathrm{NaCl}), 1 \mathrm{~mL}$ of $0.15 \mathrm{M}$ phosphate buffer ( $\mathrm{pH} 7.4)$, and $1 \mathrm{~mL}$ test solution (100 and $200 \mu \mathrm{g} / \mathrm{mL}$ of final volume) in normal saline. $0.5 \mathrm{~mL}$ of $10 \%$ rat RBC in normal saline was added. For control tests, $1 \mathrm{~mL}$ of isotonic saline was used instead of the test solution. The mixtures were incubated at $56^{\circ} \mathrm{C}$ for $30 \mathrm{~min}$. The tubes were cooled under running tap water for $20 \mathrm{~min}$. The mixtures were centrifuged and the optical density of the supernatants read at $560 \mathrm{~nm}$ [21]. The percent inhibition was calculated.

Percent inhibition $=100 \times 1-($ absorbance of test sample/absorbance of control).

\section{In vivo evaluation of anti-arthritic activity}

Formaldehyde-induced arthritis

Paw edema in the right foot of rats was induced by subplantar injection of $0.1 \mathrm{~mL}$ of $2 \%$ freshly prepared formaldehyde on day 1 and 3 of the experiment to model chronic arthritis. Formaldehyde was injected $30 \mathrm{~min}$ after drug dosing. One of the two treatments was given to the animals orally once per day for the duration of the experiment. Paw volume was measured initially and then on days $3,5,7,9$, and 11 using a plethysmometer [22].

The percentage inhibition of inflammation was calculated using the following formula:

Percentage inhibition $=\left(1-\left[\mathrm{V}_{t} / \mathrm{V}_{\mathrm{c}}\right]\right) \times 100$

Where $V_{t}$ represents the change in paw volume in the tested groups and $\mathrm{V}_{\mathrm{c}}$ represents the change in paw volume in the model group.

Complete Freund's adjuvant-induced arthritis

Adjuvant arthritis was induced in rats by injecting $100 \mu \mathrm{L}$ of CFA, subplantarly at the right hind paw to all groups, except normal control. Rats were pre-treated with test drugs/vehicle for a period of 1 week, twice a day before the induction of arthritis, and thereafter, CFA was administered and considered as day 0 of the experiment. Paw volume was measured at days $0,4,8,12,16$, and 20 following CFA injection using a plethysmometer [23].

Biochemical parameters

On the $21^{\text {st }}$ day, blood was collected from animals and used for estimation of various biochemical parameters such as serum glutamic oxaloacetic transaminase (SGOT), serum glutamic pyruvic transminase (SGPT), albumin, calcium, phosphorous, and rheumatoid factor.

Radiographical assessment

After the completion of the study (on day 22), the animals were anesthetized using ether and placed on the radiographical plate. X-ray analysis of ankle joint of rats from each group was done.

Histopathological study

On day 22, rats were anesthetized and sacrificed using $\mathrm{CO}_{2}$ chamber. The ankle joints were amputated and then fixed in $10 \%$ neutral buffered formalin solution. They were decalcified, sectioned, and stained with hematoxylin and eosin and study under the light microscope [24].

\section{Statistical analysis}

Values were expressed as mean \pm standard error of mean (SEM), $\mathrm{n}=6$. All the groups were compared with normal control using ANOVA followed by Dunnett's test. Statistically significant values were expressed at $* * \mathrm{p}<0.01$ and $* \mathrm{p}<0.05$.

\section{RESULTS}

\section{In vitro antioxidant assays}

\section{Hydrogen peroxide radical scavenging assay}

The hydrogen peroxide scavenging activity was recorded in terms of percentage inhibition. It was observed that azathioprine and pioglitazone showed prominent inhibition of free radicals with increased concentrations.

Pioglitazone produced better antioxidant potential than azathioprine. The combination of azathioprine and pioglitazone exhibited prominent inhibition of hydrogen peroxide radicals, which indicate the synergistic effect of the test drugs. The effect of the combination was found to be comparable to that of standard ascorbic acid (Fig. 1).

The half-maximal inhibitory concentration $\left(\mathrm{IC}_{50}\right.$ ) of azathioprine and pioglitazone was found to be 81 and 70 , respectively. The $\mathrm{IC}_{50}$ of the combination was found to be 56 which was comparable with standard ascorbic acid (38) (Fig. 1).

\section{Nitric oxide scavenging activity}

The nitric oxide scavenging activity was recorded in terms of percentage inhibition. It was observed that azathioprine and pioglitazone have shown prominent inhibition of the free radicals. 


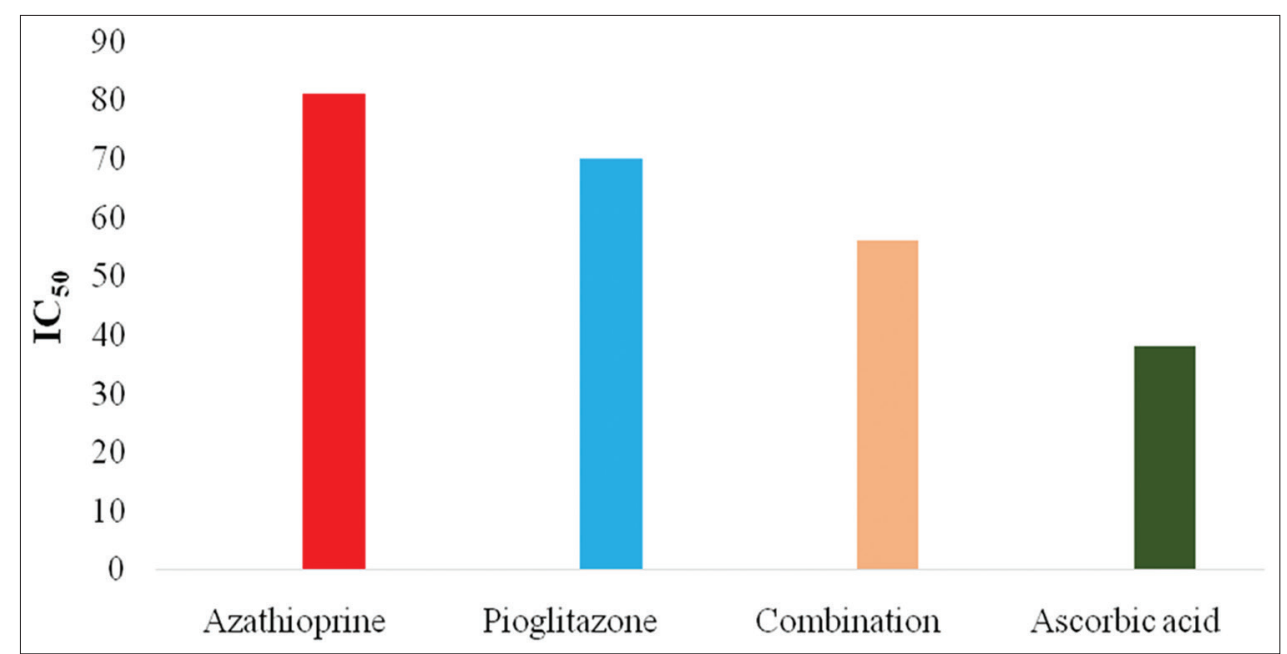

Fig. 1: Hydrogen peroxide radical scavenging assay of azathioprine, pioglitazone, and their combination

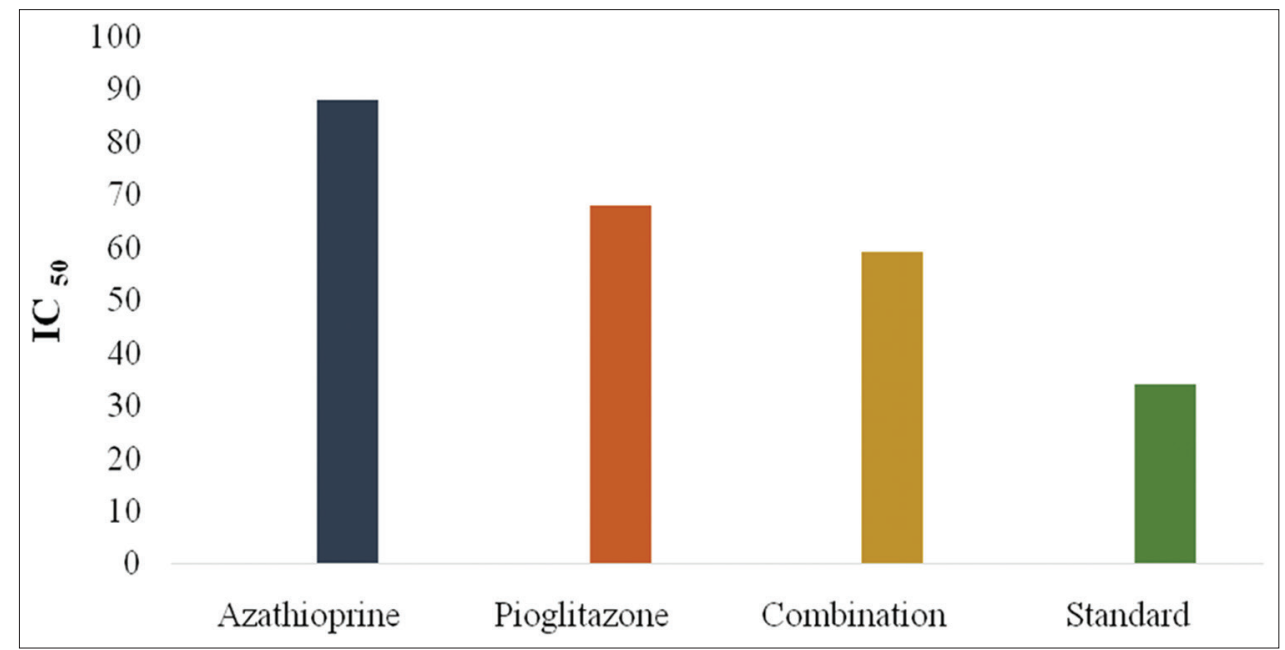

Fig. 2: Nitric oxide scavenging activity of azathioprine, pioglitazone, and their combination

The antioxidant property of pioglitazone was found to be better than that of azathioprine. The percentage inhibition was increased with increase in the concentration of the drug. The combination of azathioprine and pioglitazone exhibited significant inhibition of nitric oxide radicals which indicates the synergistic effect of the test drugs. The effect of the combination was comparable to that of standard ascorbic acid (Fig. 2).

The half-maximal inhibitory concentration $\left(\mathrm{IC}_{50}\right)$ of azathioprine and pioglitazone was found to be 88 and 68 , respectively. The $\mathrm{IC}_{50}$ of the combination was found to be 59 which was comparable with standard ascorbic acid (34) (Fig. 2).

\section{In vitro evaluation of anti-arthritic activity}

\section{Inhibition of protein denaturation method}

In inhibition of protein denaturation, azathioprine at dose 100 and $200 \mu \mathrm{g} / \mathrm{mL}$ showed of $49.5 \%$ and $68 \%$ inhibition, respectively, whereas pioglitazone at dose 100 and $200 \mu \mathrm{g} / \mathrm{mL}$ showed of $38 \%$ and $58 \%$ inhibition, respectively.

The combination of above two drugs at a dose of 100 and $200 \mu \mathrm{g} / \mathrm{mL}$ showed of $62.5 \%$ and $81.6 \%$ inhibition, respectively, which was better than that of standard indomethacin (Fig. 3).

The percentage inhibition of azathioprine, pioglitazone, their combination, and indomethacin at 100 and $200 \mu \mathrm{g} / \mathrm{mL}$ in inhibition of protein denaturation method (Fig. 3).

\section{Membrane stabilization method}

In membrane stabilization activity, azathioprine showed percent inhibition of $58.2 \%$ and $82.5 \%$ at dose 100 and $200 \mu \mathrm{g} / \mathrm{mL}$, respectively, whereas pioglitazone at dose 100 and $200 \mu \mathrm{g} / \mathrm{mL}$ showed percent inhibition of $43.5 \%$ and $71.1 \%$, respectively.

The combination of above two drugs at a dose of 100 and $200 \mu \mathrm{g} / \mathrm{mL}$ showed percent inhibition of $63.8 \%$ and $89.1 \%$, respectively, which was better than that of standard indomethacin (Fig. 4).

The percentage inhibition of azathioprine, pioglitazone, their combination, and indomethacin at 100 and $200 \mu \mathrm{g} / \mathrm{mL}$ in inhibition of membrane stabilization method (Fig. 4).

\section{In vivo evaluation of anti-arthritic activity \\ Formaldehyde-induced arthritis}

Subplantar injection of formaldehyde on the $1^{\text {st }}$ and $3^{\text {rd }}$ days of the experiment resulted in significant increase in paw volumes in Group 2 on days $3,5,7,9$, and 11 compared with mean paw volumes of untreated control group rats (Group I) ( $\mathrm{p}<0.01)$. Azathioprine-treated arthritic rats (Group 3) shown a significant decrease in mean paw volumes compared with the arthritic control group (Group II) ( $\mathrm{p}<0.01$ ). Percent inhibition rates of paw volumes were $1.47 \%, 9.2 \%, 18.9 \%, 21 \%$, and $22.5 \%$, respectively.

Pioglitazone-treated arthritic rats (Group IV) show significant improvement in mean paw volumes on days $3,5,7,9$, and 11 of the 


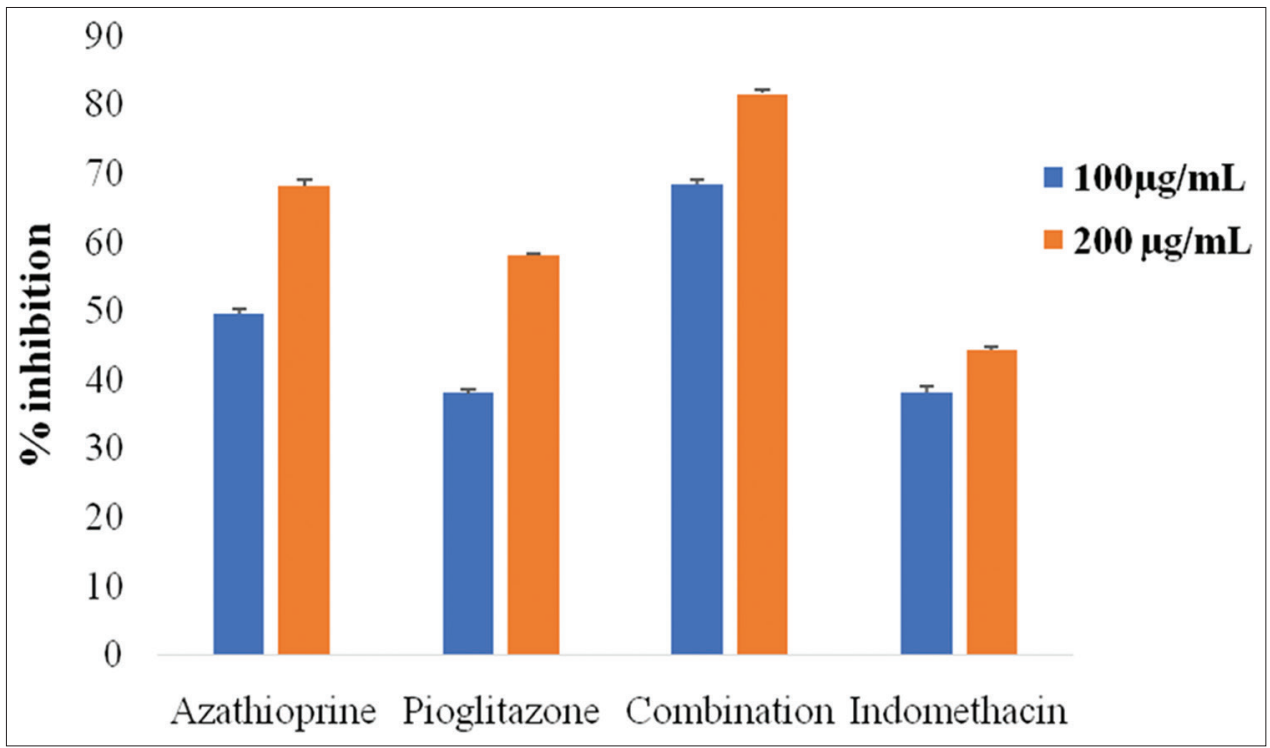

Fig. 3: Effect of azathioprine, pioglitazone, and their combination using protein denaturation method

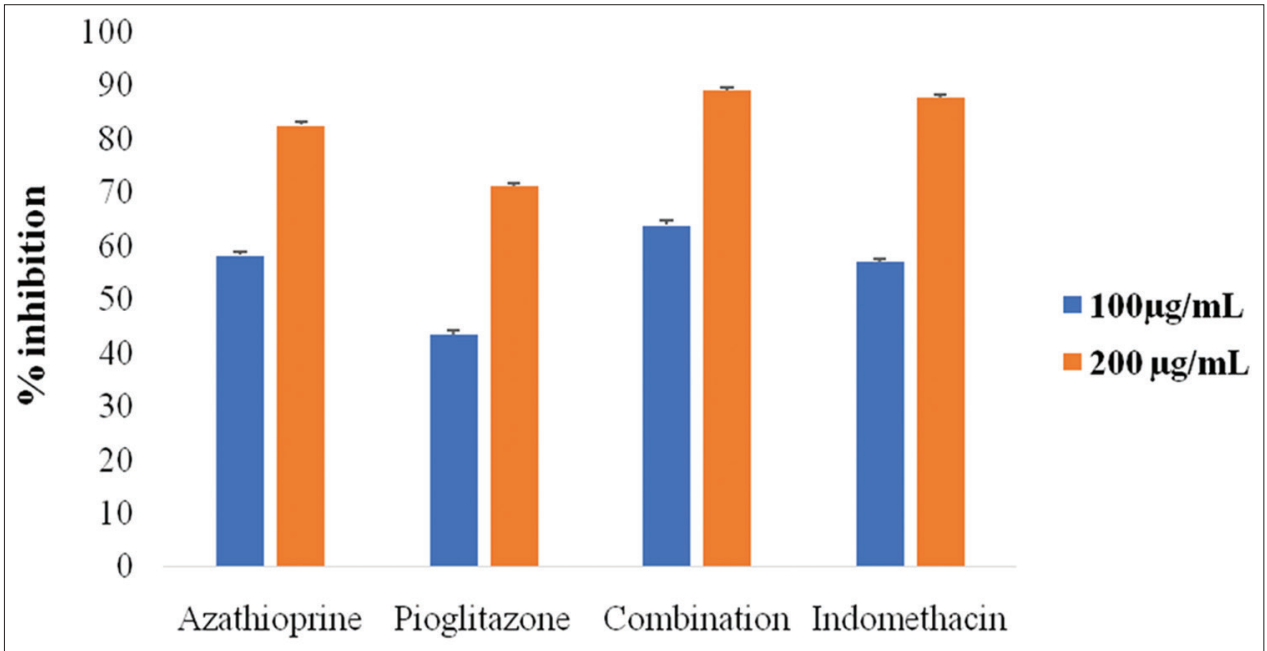

Fig. 4: Effect of azathioprine, pioglitazone, and their combination using membrane stabilization method

experiment compared with arthritic control group (Group II) $(\mathrm{p}<0.05)$. Percent inhibition rates of paw volumes were $0.73 \%, 7.8 \%, 14.1 \%$, $18.7 \%$, and $20.5 \%$, respectively.

Combination of above two drugs produced a better reduction of mean paw volumes than individual drugs $(\mathrm{p}<0.01)$. Percent inhibition rates of paw volumes were $4.4 \%, 12 \%, 22.2 \%, 26.1 \%$, and $34 \%$, respectively. The results indicate synergistic interaction between azathioprine and pioglitazone (Fig. 5).

Acute treatment with azathioprine $(4.5 \mathrm{mg} / \mathrm{kg})$, pioglitazone $(1.35 \mathrm{mg} / \mathrm{kg})$, their combination $(4.5+1.35 \mathrm{mg} / \mathrm{kg})$ and ${ }^{*} \mathrm{p}<0.05$, ${ }^{* *} \mathrm{p}<0.01$ compared with normal, tested by ANOVA followed by Dunnett's test. Data were expressed as mean \pm SEM $(n=6)$ (Fig. 5).

\section{Complete Freund's adjuvant-induced arthritis}

CFA-induced arthritis in experimental animals is one of the best and most widely used animal models since it has a close analogy to human rheumatoid disease. The results showed that the paw volume measured using plethysmometer gradually increased from the day of injection and reached its maximum $(3.64 \mathrm{~mL})$ on the $16^{\text {th }}$ day in CFA-induced rats, whereas the azathioprine $(4.5 \mathrm{mg} / \mathrm{kg})$ and pioglitazone $(1.35 \mathrm{mg} / \mathrm{kg})$ showed significant decrease in edema volume to about 1.49 and $1.68 \mathrm{~mL}$, respectively, on the $20^{\text {th }}$ day as compared to CFA-induced edematous rats. Among the drugs azathioprine produced a relatively better effect than that of pioglitazone and the combination of these two drugs showed a better effect (67.2\%) than that of individual drugs (Fig. 6).

Chronic treatment with azathioprine $(4.5 \mathrm{mg} / \mathrm{kg})$, pioglitazone $(1.35 \mathrm{mg} / \mathrm{kg})$, their combination $(4.5+1.35 \mathrm{mg} / \mathrm{kg})$ and $* \mathrm{p}<0.05$, ${ }^{* *} \mathrm{p}<0.01$ compared with normal, tested by ANOVA followed by Dunnett's test. Data were expressed as mean \pm SEM ( $n=6$ ) (Fig. 6).

\section{Biochemical parameters}

SGOT levels measured on day 21 showed higher values in case of arthritic group $(107.16 \pm 0.30)$ compared to the non-arthritic group (62.14 \pm 0.47 ). Treatment with azathioprine and pioglitazone significantly reduced the elevated SGOT levels $(76 \pm 0.55$ and $80 \pm 0.36)$ compared to arthritic control group. Azathioprine showed relatively better effect than pioglitazone. The combination of these two drugs showed a significantly better effect than that of individual drugs $(67 \pm 0.44)(\mathrm{p}<0.01)$.

There was a significant rise in SGPT levels of the arthritic group $(88.16 \pm 0.3)$ compared to the normal group $(32.5 \pm 0.42)$. Treatment with azathioprine and pioglitazone significantly reduced the elevated 


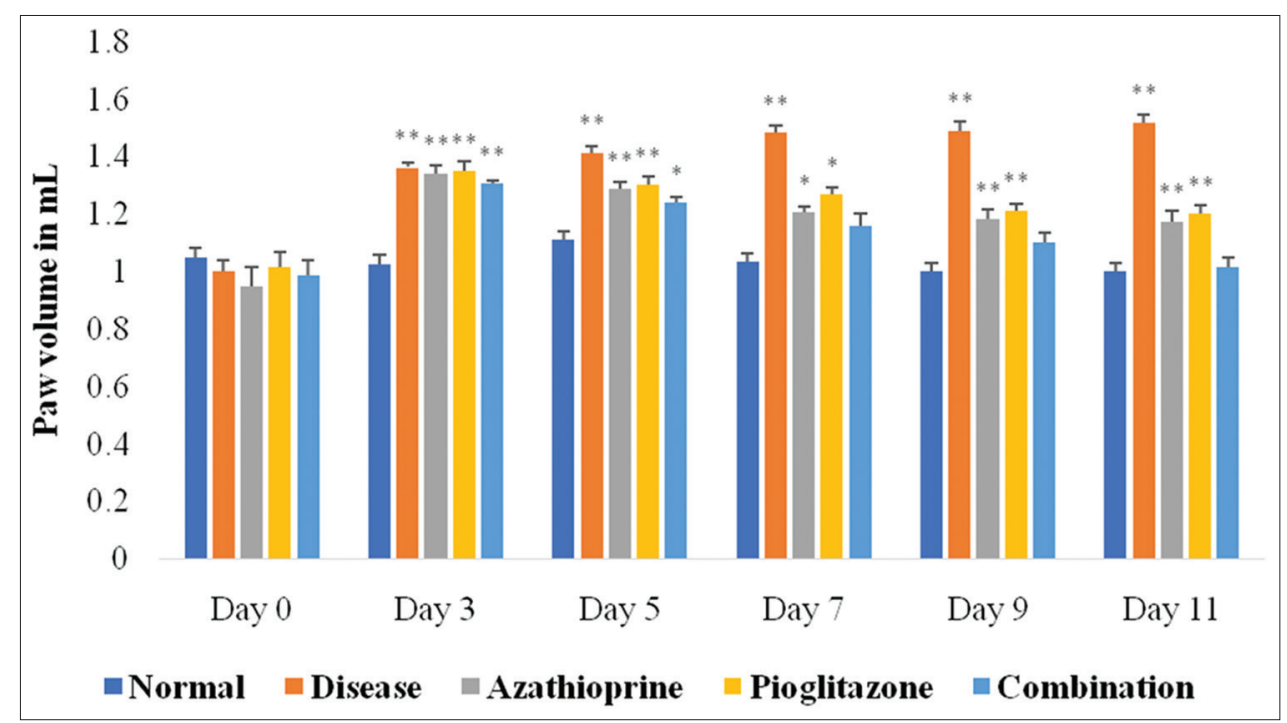

Fig. 5: Effect of azathioprine, pioglitazone, and their combination using formaldehyde-induced arthritis

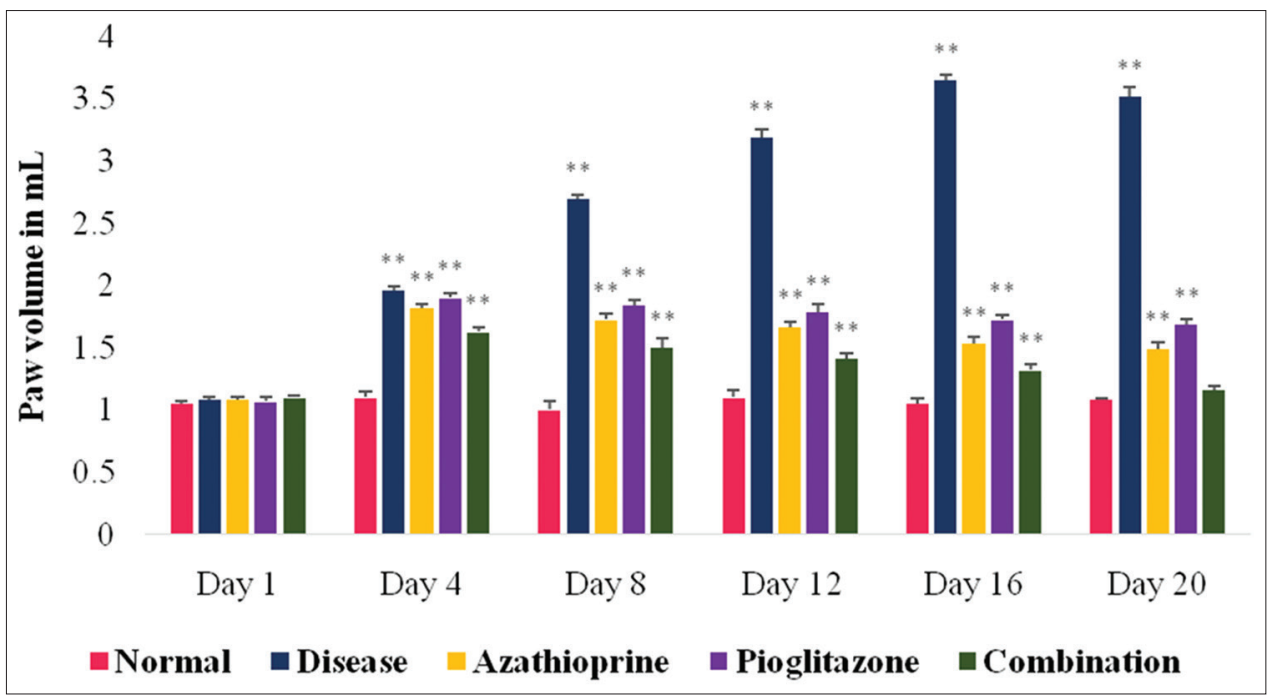

Fig. 6: Effect of azathioprine, pioglitazone, and their combination using complete Freund's adjuvant-induced arthritis

SGPT levels $(54 \pm 0.36$ and $61.16 \pm 0.47)$ compared to arthritic control group. Azathioprine showed relatively better effect than pioglitazone. The combination of these two drugs exhibited a significantly better effect than that of individual drugs $(41.6 \pm 0.4)(\mathrm{p}<0.01)$.

Albumin levels measured on the day 21 significantly showed reduced values in the arthritic group $(2.34 \pm 0.24)$ compared to the non-arthritic group $(4.87 \pm 0.23)$. Treatment with azathioprine and pioglitazone significantly increased the albumin levels $(3.82 \pm 0.18$ and $4.13 \pm 0.21)$ compared to arthritic control group. Pioglitazone showed relatively better effect than azathioprine. The combination of these two drugs produced a significantly better effect than that of individual drugs ( $4.52 \pm 0.26)$.

Calcium levels were found to reduce significantly in the arthritic group $(4.89 \pm 0.37)$ and compared to the non-arthritic group $(11.39 \pm 0.2)$. Treatment with azathioprine and pioglitazone significantly increased the calcium levels $(8.68 \pm 0.24$ and $7.93 \pm 0.21)$ compared to arthritic control group. Azathioprine showed relatively better effect than pioglitazone. The combination of these two drugs showed a significantly better effect than that of individual drugs $(9.61 \pm 0.51)(\mathrm{p}<0.01)$.

Phosphorous levels were found to significantly reduce in the arthritic group $(2.53 \pm 0.18)$ compared to the non-arthritic group (7.81 \pm 0.19$)$.
Treatment with azathioprine and pioglitazone significantly increased the phosphorous levels $(6.02 \pm 0.19$ and $5.38 \pm 0.24)$ compared to arthritic control group. Azathioprine showed relatively better effect than pioglitazone. The combination of these two drugs showed a significantly better effect than that of individual drugs $(7.11 \pm 0.25)(\mathrm{p}<0.01)$.

Rheumatoid factor was significantly elevated in the arthritic group $(18 \pm 0.50)$ and least in the non-arthritic group $(8.66 \pm 0.17)$. Treatment with azathioprine and pioglitazone significantly decreased the Rheumatoid Factor (RF) levels $(10.4 \pm 0.39$ and $12.25 \pm 0.22)$ compared to arthritic control group. Azathioprine showed relatively better effect than pioglitazone. The combination of these two drugs exhibited a significantly better effect than that of individual drugs $(9.28 \pm 0.21)$ $(p<0.01)$ (Figs. 7 and 8)

Chronic treatment with azathioprine $(4.5 \mathrm{mg} / \mathrm{kg})$, pioglitazone $(1.35 \mathrm{mg} / \mathrm{kg})$, their combination $(4.5+1.35 \mathrm{mg} / \mathrm{kg})$, and $* \mathrm{p}<0.05$, ${ }^{* *} \mathrm{p}<0.01$ compared with normal, tested by ANOVA followed by Dunnett's test. Data were expressed as mean \pm SEM ( $n=6$ ) (Figs. 7 and 8).

\section{Radiological examinations}

The improved anti-inflammatory efficacy of azathioprine in combination with pioglitazone was substantiated by radiological examination 


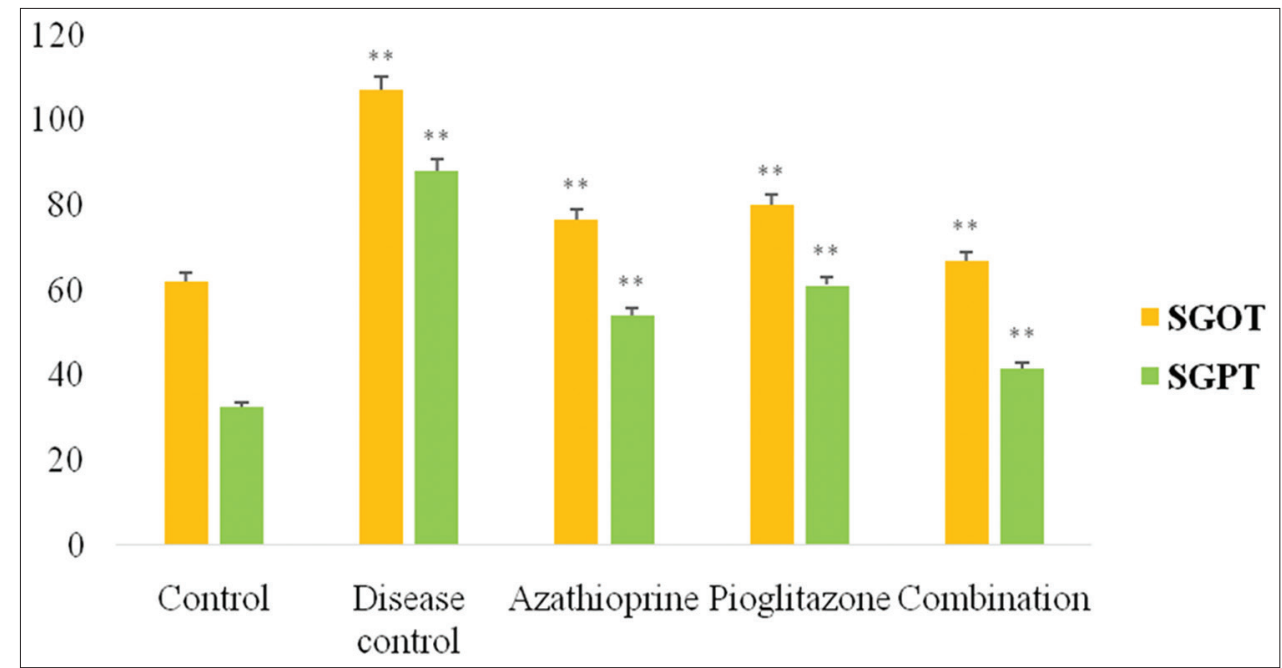

Fig. 7: Levels of serum glutamic oxaloacetic transaminase and serum glutamic pyruvic transminase in complete Freund's adjuvant-induced arthritis

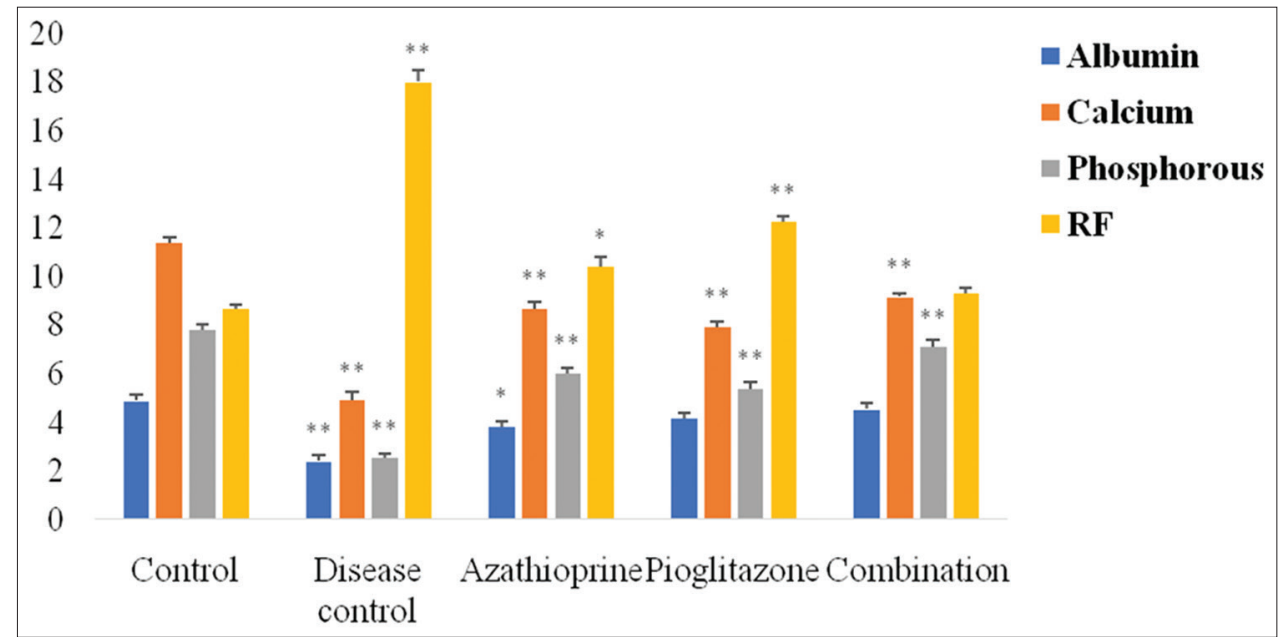

Fig. 8: Levels of albumin, calcium, phosphorous, and RF in complete Freund's adjuvant-induced arthritis

of the animals. Arthritic rats showed bone erosion representing bone destruction, mild-to-moderate cartilage damage. This may be attributed to chronic exposure of bones to proinflammatory chemical mediators such as TNF- $\alpha$ and IL-1, stimulating the enhanced production of proteolytic enzymes by chondrocytes resulting in degradation of cartilage. In case of azathioprine, pioglitazone, and their combination, these changes were observed to have normalized, and the effect of combination has protected the joint tissue better than that of individual drugs (Fig. 9).

\section{Histopathological studies}

There was dense lymphocyte infiltration in subcutaneous fat with focal cartilage erosion and foreign-body giant cell reaction in the disease control group. There was mild-to-moderate synovial cell hyperplasia with pannus formation, and no signs of cartilage erosion in animals treated with azathioprine and pioglitazone. There was no synovial cell hyperplasia, pannus formation, and cartilage erosion in animals treated with both azathioprine and pioglitazone indicating the better effect of combination (Fig. 10).

(a) Joint tissues of normal control rat. Absence of synovial hyperplasia, bone erosion, inflammation and cartilage destruction. (b) Joint tissues of disease control rat. Dense infiltration of lymphocytes in subcutaneous fat focal cartilage erosion and foreign-body giant cell reaction. (c) Joint tissues of azathioprine-treated group rat. Mild synovial hyperplasia with pannus formation but no signs of cartilage erosion. (d) Joint tissues of pioglitazone-treated group. Moderate synovial cell hyperplasia with pannus formation and foreign-body giant cell reaction without signs of cartilage erosion. (e) Joint tissues of azathioprine+pioglitazone-treated group. No synovial cell hyperplasia, pannus formation, and cartilage erosion within discriminate focal fat necrosis (Fig. 10).

\section{DISCUSSION}

ROS, as well as reactive nitrogen species, can damage basic articular constituents either directly or indirectly and lead to the clinical expression of inflammatory arthritis. Hydrogen peroxide and nitric oxide are major free radicals implicated in the pathogenesis of RA [3]. Hence, the antioxidant potential of azathioprine, pioglitazone, and their combination was evaluated using hydrogen peroxide and nitric oxide radical scavenging activity models.

Hydrogen peroxide, being a weak oxidizing agent, can inactivate few enzymes by oxidation of essential thiol $(-\mathrm{SH})$ groups. $\mathrm{H}_{2} \mathrm{O}_{2}$ probably reacts with $\mathrm{Fe}^{2+}$ and possibly $\mathrm{Cu}^{2+}$ ions to form hydroxyl radical, which may produce many of its damaging effects [25]. Azathioprine, pioglitazone, and their combination showed prominent hydrogen peroxide scavenging activity. The $\mathrm{H}_{2} \mathrm{O}_{2}$ scavenging activity of azathioprine and pioglitazone might be attributed to the electron 

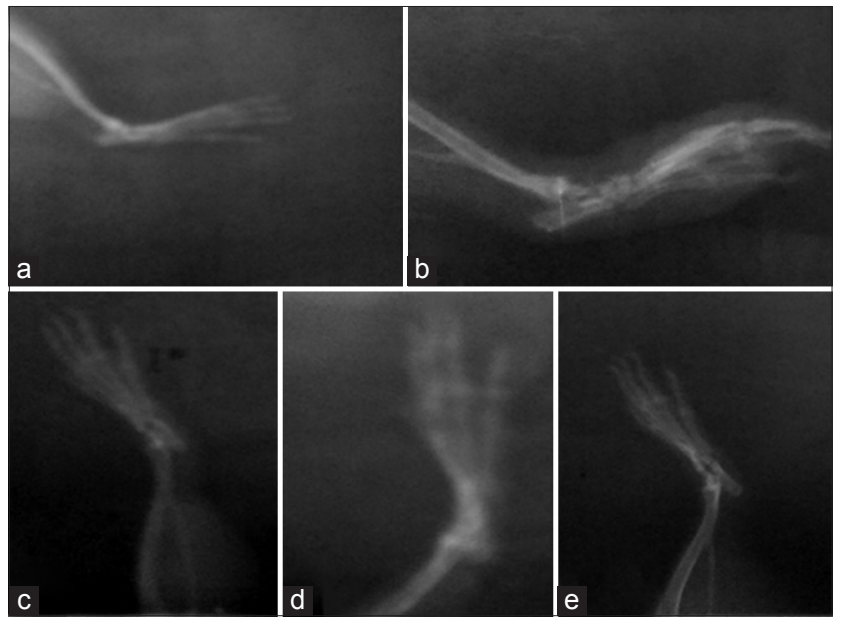

Fig. 9: Radiographical images of the hind paw radiographical images of the hind paw (a) normal rat, (b) diseased rat (arthritis), (c) azathioprine-treated rat, (d) pioglitazone-treated rat,

(e) combination (azathioprine+pioglitazone)-treated rat (Fig. 9)

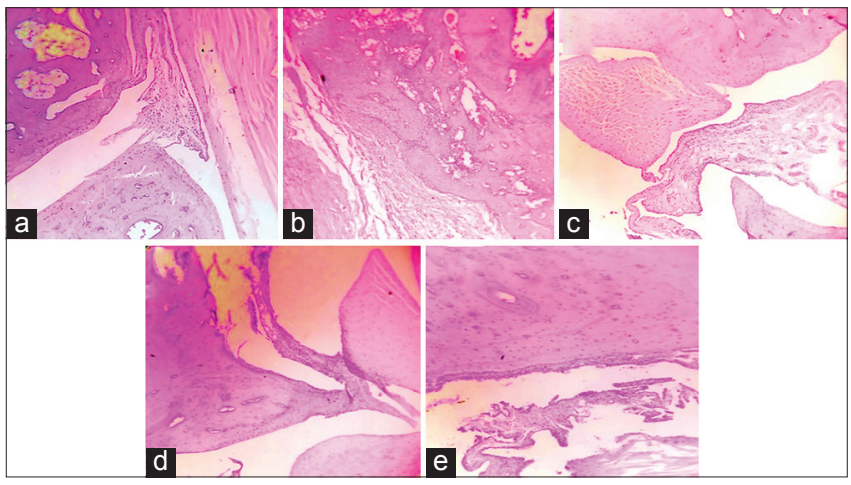

Fig. 10: Histopathological studies of rat (a), normal (b), diseased (arthritis), (c) azathioprine-treated, (d) pioglitazone-treated, (e) combination (azathioprine+pioglitazone) treated

donating nature of mercaptopurine and 2,4-thiozolidinedione, respectively, which neutralizes hydrogen peroxide into water.

NO reacts with $\mathrm{O}_{2}$ radical to form peroxynitrite radicals (ONOO-) that damages biomolecules such as proteins, lipids, and nucleic acids [26]. During the process of inflammation, cells of the immune system produce superoxide radicals by the help of Reduced Nicotinamide Adenine Dinucleotide Phosphate (NADPH) oxidase, which plays an important role in the induction of vascular complications [27]. Azathioprine and pioglitazone significantly inhibit generation of $\mathrm{NO}$ and $\mathrm{HO}$ radicals in a dose-dependent manner. This effect of the test drugs might be due to their electron donating nature. The synergistic interaction observed with the combination of drugs in both models might be due to the combined electron donating nature of the two drugs.

RA is usually characterized macroscopically by paw edema and a decrease in body weight. In vitro anti-arthritic activity of the azathioprine, pioglitazone, and their combination was carried out by the protein denaturation and membrane stabilization method.

Denaturation of protein is a kind of cellular response to various stimuli that influence homeostasis. Protein denaturation and macroglobulin formation are suggested to cause the protein to become autoantigenic, which initiates the immune response and produce biochemical changes in connective tissue which ultimately leads to RA [28]. In the present study, azathioprine and pioglitazone produced dose-dependent inhibition of protein denaturation and its subsequent macroglobulin formation and autoantigen production. The combination of the above two drugs produced synergistic interaction which might be due to the reinforcement of azathioprine action by pioglitazone.

Exposure of RBCs to injurious substances such as hypotonic medium, heat, methyl salicylate, or phenylhydrazine results in the lysis of the membranes with subsequent hemolysis and oxidation of hemoglobin. The inhibition of hypotonicity and heat-induced RBC membrane lysis was taken as a measure of the mechanism of anti-inflammatory activity because RBC membranes are similar to lysosomal membrane components [29]. Both azathioprine and pioglitazone showed prominent inhibition of the hemolytic effect of the hypotonic solution and its consequent increased permeability caused by inflammatory mediators. Combination of the above two drugs produced significant and better membrane stabilization due to similarity in the prevention of hypotonic solution-induced hemolysis.

In the present study, the anti-arthritic activity of azathioprine, pioglitazone, and their combination was evaluated using two in vivo experimental models of arthritis, namely formaldehyde and CFAinduced arthritis.

Formaldehyde develops biphasic localized inflammation. In early phase (neurogenic phase), substance $P$ is released, while in the late phase (Inflammatory phase), histamine, serotonin, bradykinin, and prostaglandins are produced, which results in pronounced vasodilation and permeability [30]. The results of the present study showed that azathioprine and pioglitazone subdued proliferative edematous reaction, which tenably could be due to inhibition of the late phase involving the inflammatory mediators. The combination showed synergistic effect due to the prominent inhibitory effect on the release of inflammatory mediators by preventing activation of macrophage. Thus, to further confirm the activity of the test drugs, their efficacy in reducing joint inflammation in CFA-induced arthritis in rats was evaluated.

Adjuvant arthritis has been used as a model of subchronic or chronic inflammation in rats andis highly relevantto the study of pathophysiology and pharmacological control of inflammatory processes, as well as for the screening of anti-arthritic drugs [31,32]. CFA produces arthritis in two phases - an acute periarticular inflammation followed by a phase of bone involvement. It provokes joint swelling, synovial membrane inflammation, and cartilage destruction.

Administration of azathioprine and pioglitazone showed significant inhibition of paw inflammation, which might be due to their effect on the first phase of CFA-induced inflammation, i.e., activation of macrophages and the subsequent release of inflammatory mediators. Combination of the two drugs produced synergistic effect due to their combined inhibitory action on the release of inflammatory cytokines.

RA involves liver and kidney function impairment along with joint tissue damage. Under such conditions, there is an increase in serum levels of aminotransferases (SGOT and SGPT) due to the cellular release of these enzymes from affected tissues. Serum albumin acts as a negative acute phase indicator of arthritis both in rats and humans [33]. There is reduced calcium and phosphorous which might be due to decreased calcitriol and tissue hypoxia due to increased Adenosine Triphosphate (ATP) degradation. Hypertrophy and hyperplasia create a hypoxic environment in synovial joints, and this was improved significantly on azathioprine and pioglitazone treatment [34].

$\mathrm{RF}$ is an autoantibody directed against the Fc portion of IgG and serves as a key serological marker. It forms immune complexes that contribute to the progression of RA [35,36].

The anti-arthritic activity of the test drugs is further depicted by reduction of biochemical parameters such as SGOT, SGPT, and rheumatoid factor and elevation of serum albumin, calcium, and phosphorous. 


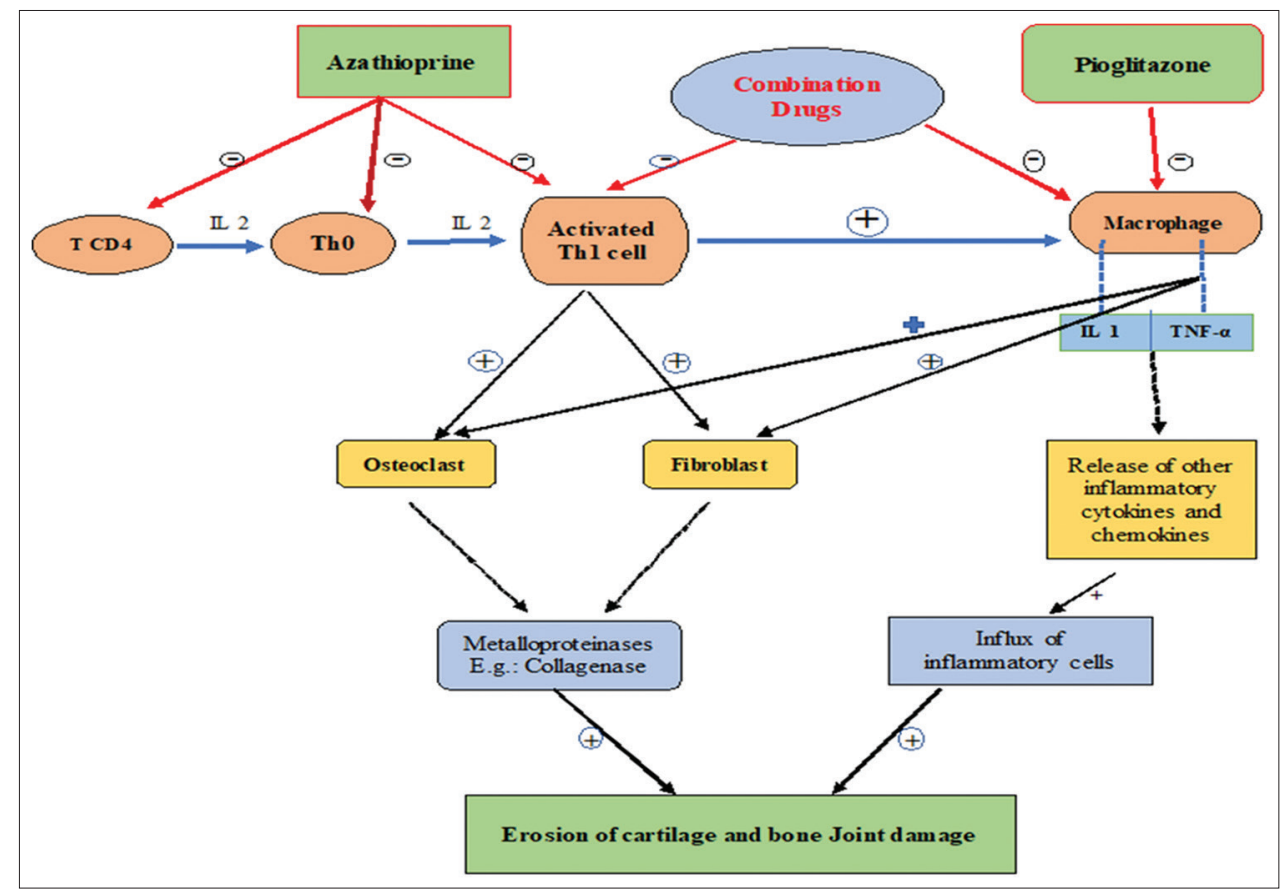

Fig. 11: Possible mechanism of interaction

The activity of test compounds was further corroborated by radiological and histopathological studies. The possible synergistic interaction might be due to the inhibition of the release of matrix metalloproteinases by azathioprine and inhibition of inflammatory mediators by pioglitazone which together prominently alleviated erosion of cartilage and subsequent bone damage (Fig. 11).

Possible mechanism of synergistic interaction between azathioprine and pioglitazone (Fig. 11).

\section{CONCLUSIONS}

The combination of azathioprine and pioglitazone exhibited significant anti-arthritic activity than their counterparts, which might be due to their free radical scavenging activity and inhibitory effect on the release of inflammatory mediators. This study clearly highlights add on the benefit of combination therapy over monotherapy in the management of arthritis. This should be further evaluated clinically to prove its efficacy in humans, which can result in the development of a better remedy for the management of RA.

\section{ACKNOWLEDGMENTS}

Authors are grateful to the Principal and management of Gokaraju Rangaraju College of Pharmacy for providing all the facilities required to carry out this work.

\section{AUTHORS' CONTRIBUTIONS}

Veeresh Babu $\mathrm{P}$ is the research guide and designed the present work. Soundarya V is a research student who executed the work. Ganga Raju $\mathrm{M}$ is the Head of the Department who gave necessary inputs to work.

\section{CONFLICTS OF INTEREST}

There are no conflicts of interest.

\section{REFERENCES}

1. Gupta RK, Patel AK, Shah N, Chaudhary AK, Jha UK, Yadav UC, et al. Oxidative stress and antioxidants in disease and cancer: A review. Asian Pac J Cancer Prev 2014;15:4405-9.

2. Fotina AA, Fisinin I, Surai PF. Recent developments in usage of natural antioxidants to improve chicken meat production and quality. Bulg $\mathrm{J}$ Agric Sci 2013;19:889-96.

3. Hadjigogos K. The role of free radicals in the pathogenesis of rheumatoid arthritis. Panminerva Med 2003;45:7-13.

4. Klareskog L, Catrina AI, Paget S. Rheumatoid arthritis. Lancet 2009;373:659-72.

5. Symmons D, Turner G, Webb R, Asten P, Barrett E, Lunt M, et al. The prevalence of rheumatoid arthritis in the United Kingdom: New estimates for a new century. Rheumatology (Oxford) 2002;41:793-800.

6. Englund M, Jöud A, Geborek P, Felson DT, Jacobsson LT, Petersson IF, et al. Prevalence and incidence of rheumatoid arthritis in Southern Sweden 2008 and their relation to prescribed biologics. Rheumatology (Oxford) 2010;49:1563-9.

7. Siebert S, Tsoukas A, Robertson J, McInnes I. Cytokines as therapeutic targets in rheumatoid arthritis and other inflammatory diseases. Pharmacol Rev 2015;67:280-309.

8. Firestein GS. Evolving concepts of rheumatoid arthritis. Nature 2003;423:356-61.

9. Lee DM, Weinblatt ME. Rheumatoid arthritis. Lancet 2001;358:903-11.

10. Gibofsky A. Combination therapy for rheumatoid arthritis in the era of biologicals. HSS J 2006;2:30-41.

11. Paul S, Das AP, Bhattacharjee S. Rheumatoid arthritis: Molecular basis and cures from nature. Int J Pharm Pharm Sci 2015;7:30-9.

12. Rang H, Ritter J, Flower R, Henderson G. Rang and Dale's Pharmacology. $8^{\text {th }}$ ed. London: Churchill Livingstone; 2015. p. 325-7.

13. Fahmi H, Di Battista JA, Pelletier JP, Mineau F, Ranger P, MartelPelletier $\mathrm{J}$, et al. Peroxisome proliferator-activated receptor gamma activators inhibit interleukin-1beta-induced nitric oxide and matrix metalloproteinase 13 production in human chondrocytes. Arthritis Rheum 2001;44:595-607.

14. Clark RB, Bishop-Bailey D, Estrada-Hernandez T, Hla T, Puddington L, Padula SJ, et al. The nuclear receptor PPAR gamma and immunoregulation: PPAR gamma mediates inhibition of helper $\mathrm{T}$ cell responses. J Immunol 2000;164:1364-71.

15. Chinetti G, Griglio S, Antonucci M, Torra IP, Delerive P, Majd Z, et al. Activation of proliferator-activated receptors alpha and gamma induces apoptosis of human monocyte-derived macrophages. J Biol Chem 1998;273:25573-80

16. Harris SG, Phipps RP. The nuclear receptor PPAR gamma is expressed by mouse T lymphocytes and PPAR gamma agonists induce apoptosis. Eur J Immunol 2001;31:1098-105.

17. Chung LY, Schmidt RJ, Andrews AM, Turner TD. A study of hydrogen peroxide generation by, and antioxidant activity of, granuflex (DuoDERM) hydrocolloid granules and some other hydrogel/hydrocolloid wound management materials. Br J Dermatol 
1993;129:145-53.

18. Jagetia GC, Baliga MS. The evaluation of nitric oxide scavenging activity of certain Indian medicinal plants in vitro: A preliminary study. J Med Food 2004;7:343-8.

19. Deshpande V, Jadhav VM, Kadam VJ. In-vitro anti-arthritic activity of Abutilon indicum (Linn.) Sweet. J Pharm Res 2009;2:644-5.

20. Gupta SK, Gupta A, Pakash D. In vitro antiarthritic activity of ethanolic extract of Callicarpa macrophylla. Int Res J Pharm 2013;4:160-2.

21. Sakat SS, Juvekar AR, Gambhire MN. In vitro antioxidant and antiinflammatory activity of methanol extract of Oxalis corniculata Linn. Int J Pharm Pharm Sci 2010;2:146-55.

22. Kyei S, Kofuor G, Boampong J. The efficacy of aqueous and ethanolic leaf extracts of Pistia stratiotes Linn in the management of arthritis and fever. J Med Biomed Sci 2012;1:29-37.

23. Yeom MJ, Lee HC, Kim GH, Lee HJ, Shim I. Antiarthritic effects of Ephedra sinica S TAPF herb-acupuncture: Inhibition of lipopolysaccharide-induced inflammation and adjuvant-induced polyarthritis. J Pharmacol Sci 2006;100:41-50.

24. Mayur P, Kumar A, Maheshwar KK. Establishment of a mechanism of poly herbal formulation for anti-rheumatism. Int J Pharm Pharm Sci 2016;8:91-5.

25. Miller MJ, Sadowsak-Krowicka H, Chotinaruemol S, Kakkis JK, Clark DA. Amelioration of chronic ileitis by nitric oxide synthase inhibition. J Pharmacol Exp Ther 1993;264:11-6.

26. Yermilov V, Rubio J, Becchi M, Friesen MD, Pignatelli B, Ohshima H, et al. Formation of 8-nitroguanine by the reaction of guanine with peroxynitrite in vitro. Carcinogenesis 1995;16:2045-50.

27. Dröge W. Free radicals in the physiological control of cell function.
Physiol Rev 2002;82:47-95

28. Jayaprakasam R, Ravi T. Evaluation of anti-arthritic activity of the root extract of Acalypha indica Linn. Using in vitro techniques. Int $\mathrm{J}$ Phytopharm 2013;2:169-73.

29. Anosike CA, Obidoa O, Ezeanyika LU. The anti-inflammatory activity of garden egg (Solanum aethiopicum) on egg albumin-induced oedema and granuloma tissue formation in rats. Asian Pac J Trop Med 2012;5:62-6

30. Bischoff SC. Quercetin: Potentials in the prevention and therapy of disease. Curr Opin Clin Nutr Metab Care 2008;11:733-40.

31. Besson J, Guilbaud G. The Arthritic Rat as a Model of Clinical Pain? International Congress Series. New York: Excepta Medica Elsevier; 1988. p. 257.

32. Butler SH, Godefroy F, Besson JM, Weil-Fugazza J. A limited arthritic model for chronic pain studies in the rat. Pain 1992;48:73-81.

33. Martínez A, Fernández-Arquero M, Pascual-Salcedo D, Conejero L, Alves H, Balsa A, et al. Primary association of tumor necrosis factorregion genetic markers with susceptibility to rheumatoid arthritis. Arthritis Rheum 2000;43:1366-70.

34. Manivannan P, Jaleel CA, Kishorekumar A, Sankar B, Somasundaram R, Panneerselvam R, et al. Protection of Vigna unguiculata (L.) Walp. Plants from salt stress by paclobutrazol. Colloids Surf B Biointerfaces 2008;61:315-8.

35. Arnett FC, Edworthy SM, Bloch DA, McShane DJ, Fries JF, Cooper NS, et al. The American rheumatism association 1987 revised criteria for the classification of rheumatoid arthritis. Arthritis Rheum 1988;31:315-24

36. Scott DL, Wolfe F, Huizinga TW. Rheumatoid arthritis. Lancet 2010;376:1094-108 